\title{
Effects of Hand Care Therapy on Reducing the Conversion Rate from MCI to Dementia and Role of COVID-19 as Non-Pharmacotherapy
}

\section{Seigo Koura1, Akiko Ikeda1,2, Yasuhiko Fujioka3 ${ }^{3}$, Yasuhiro Mizogami', Kentaro Higashi ${ }^{5}$, Takeshi Oshikawa ${ }^{1}$}

${ }^{1}$ Faculty of Rehabilitation, Nishikyusyu University, Kanzaki City, Japan

${ }^{2}$ Sophia Phyto-Therapy College, Tokyo, Japan

${ }^{3}$ Fujioka Hospital, Saga City, Japan

${ }^{4}$ MIZ Holdings Ltd., Saga City, Japan

${ }^{5}$ Social Welfare Corporation Kanjikai, Miyakonojyo City, Japan

Email: symkoura3@gmail.com

How to cite this paper: Koura, S., Ikeda, A. Fujioka, Y., Mizogami, Y., Higashi, K. and Oshikawa, T. (2020) Effects of Hand Care Therapy on Reducing the Conversion Rate from MCI to Dementia and Role of COVID-19 as Non-Pharmacotherapy. Open Journal of Therapy and Rehabilitation, 8, 42-52.

https://doi.org/10.4236/ojtr.2020.83004

Received: May 11, 2020

Accepted: June 7, 2020

Published: June 10, 2020

Copyright $\odot 2020$ by author(s) and Scientific Research Publishing Inc. This work is licensed under the Creative Commons Attribution International License (CC BY 4.0).

http://creativecommons.org/licenses/by/4.0/

(c) (i) Open Access

\begin{abstract}
Dementia needs to be addressed by various researchers to reduce the risk of morbidity and progression. And dementia was regarded as one of lifestyle-related diseases, and it is estimated that about $10 \%$ of MCI (Mild cognitive impairment) progresses to dementia in one year. In this study, we examined whether hand care therapy (HCT) as one of passive horticultural therapy was effective in preventing dementia/MCI. In result, the use of HCT was shown to be effective in preventing dementia and $\mathrm{MCI}$ illness and slowing progression. The elderly people tended to decrease iADL year by year, but the HCT group did not. In addition, the senile depressive tendency, which is said to be increasing year by year, tended to be reduced in the HCT-treated group. This is thought to be due to not only the healing effect of the massage by HCT treatment and the effect of transmitting the pleasant stimulus from the tactile sense to the frontal lobe, but also the true communication effect created by sitting gently and touching the hand. This HCT technique can improve the euphoria of the treated side and the treated side. Therefore, it can be expected that the autoimmunity of all people involved can be improved, and it can be judged to be promising as a preventive technique and non-pharmacotherapy for lifestyle-related diseases and various infectious diseases like COVID-19.
\end{abstract}

\section{Keywords}

Dementia, MCI, Conversion, Hand Care, Prevention, COVID-19 


\section{Introduction}

Psychogeriatric medical care often takes time. Particularly, the care for a person with dementia takes more time. Therefore, not only the care of the psychological conditions of the elderly person, but also the care of the medical person or family caregiver side is important. Multi-sensory stimulation is beneficial to a wide variety of conditions typical of geriatric patients and changes appeared in muscle tension, skin conductance and pulse that correlate with reduced blood pressure [1] [2] [3]. Various studies of horticultural therapy programs demonstrated the positive effects on schizophrenic behavior and those suffering from depression [4]. In other words, engaging in horticultural activities may help improve the stability of the mind and generally facilitate a much broader and more positive attitude.

It has been reported that students participating in horticulture therapy programs developed a greater interest in the welfare of others and that the student's own feelings became more positive [5] [6]. Horticultural therapy is based on the philosophy that the activities to be carried out will also be stimulating to the senses. It is one big characteristic of the horticultural therapy, and it was an advantage [7]. On the other hand, the dynamics of the senses play an important role beyond mere reason and sensibility in people's lives. The hand care therapy (HCT) included in the horticultural therapy which is the alternative medicine that utilized a plant, or its essential oil is utilized in various application scenes.

In recent studies, HCT which was not active horticultural therapy but uses plant components as a passive horticultural therapy or aromatherapy technique, was expecting applicable to patients with severe dementia who cannot apply active horticultural therapy [8] [9].

On the other hand, dementia is an important disease whose morbidity and progress must be prevented. Dementia needs to be addressed by various researchers to reduce the risk of morbidity and progression. And dementia was regarded as one of lifestyle-related diseases, and it is estimated that about $10 \%$ of MCI (Mild cognitive impairment) progresses to dementia in one year [10].

From the viewpoint of prevention of the progress, we examined how HCT using high-quality vegetable oil affects cognitive, iADL and senile depression.

\section{Subjects and Methods}

We investigated whether HCT was effective in preventing the transition from mild cognitive impairment (as follow, MCI) to primary dementia, and examined changes in the emotions of occupational therapy students who are part of HCT practitioners.

All hand care treatments were handled by hand care therapists certified by the Japan Society of Phyto-therapy. Hand care therapists also included occupational therapy students. Also, all evaluations were performed by occupational therapists. 


\subsection{Subjects}

\section{Elderly Subjects}

The elderly in this study lived in A city, with a population of about 160,000 , $31.8 \%$ of those aged 65 and over and $16.1 \%$ of those aged 75 and over, which was the average region in Japan.

\subsection{Methods}

\subsubsection{Study Design}

The study design is shown in Figure 1. We recruited 320 participants community-dwelling adults aged 70 years or older with memory problems. All were participants in community health classes and informed consent of evaluation was obtained from all participants prior to their inclusion in the study. The informed consent also confirmed the provision of feedback on the protocol and the data obtained, and all study participants solicited for feedback.

The group A had 24 elderly patients who underwent HCT on a weekly basis in addition to their regular care programs $(84.1 \pm 4.3$ years). The placebos A consisted of 22 elderly persons who responded only to regular care programs (81.9 \pm 3.4 years).

The group B had 22 elderly patients who underwent HCT on a weekly basis in addition to their regular local health classes $(83.3 \pm 5.1$ years). The placebos $B$ consisted of 32 elderly persons who responded only to regular local health classes (82.7 \pm 3.8 years) .

Occupational therapists or caregivers performed a cognitive assessment of MMSE and MoCa-J on the 320 recruited patients, and 72 were "MCI suspected". Seventy-two elderly persons suspected of having MCI were divided into 34 persons who used a daycare-type elderly welfare facility and 32 persons who did not.

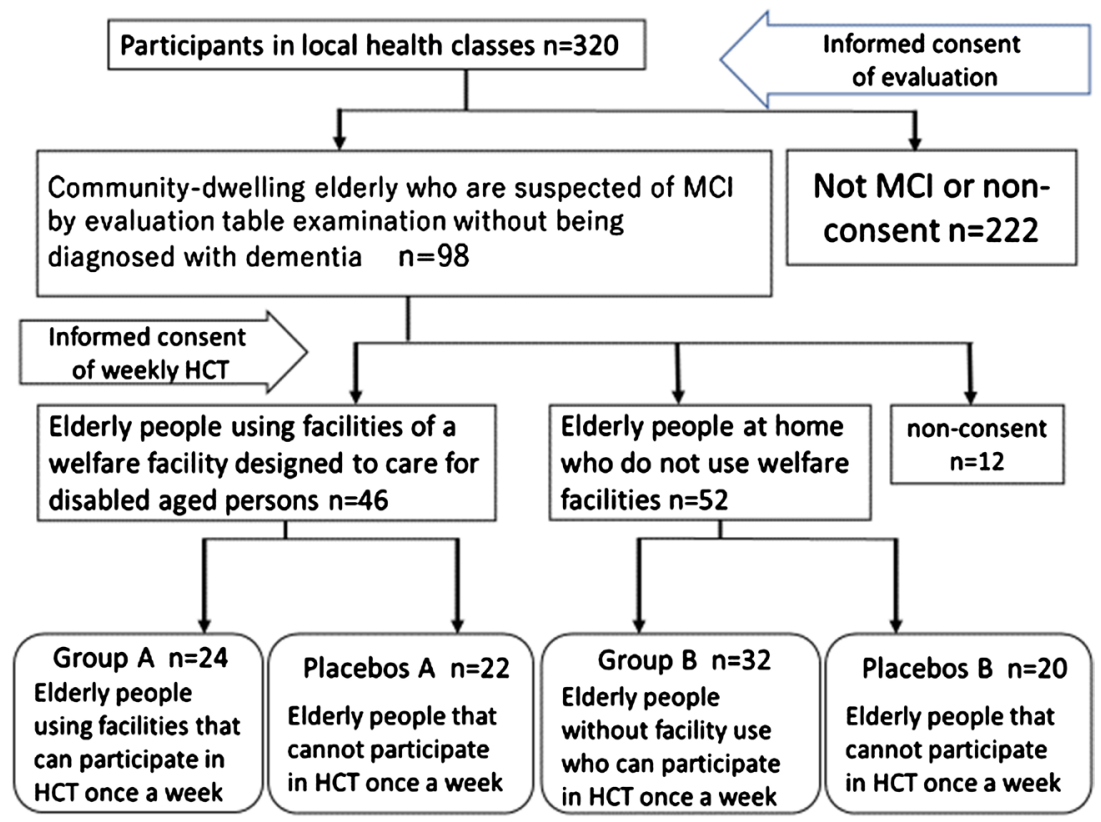

Figure 1. Flow chart for selection of HCT group and placebo group. 
Of the 34 persons using the outpatient-type elderly welfare facilities, 24 patients who wished to undergo HCT once a week were classified as Group A, and 10 persons who did not wish to receive HCT were classified as a placebo group. Among the 32 persons who did not use the outpatient-type elderly welfare facilities, 22 persons who wished to undergo HCT once a week were group B, and 10 persons who did not wish to do so were added to the placebo group.

The cognitive evaluation, iADL, and depression evaluation performed at this time were baseline values, and evaluation was continued every three months thereafter.

\subsubsection{HCT Design}

The times required for every event were preparation; 2 - $3 \mathrm{~min}$, Base Line Resting; 3 min, Interval 1; 1 min, Right hand HCT; 5 - 7 min, Interval 2; 1 - 2 min, Left hand HAT: 5 - 7 min, Rest after HAT; 3 - 5 min.

\subsection{Ethical Considerations}

We strictly observed the Helsinki Declaration of 2015 (revised in 2013), and, explained the purpose and outline of this study to them and obtained informed consent from them beforehand. All procedures were approved by the Nishikyushu University (Saga, Japan) Ethics Committee (H29-5).

\subsection{Equipment and Scales}

\subsubsection{Changes in Cognition, Life, and Depression Evaluation over Time with HCT}

The elderly persons with Mini-Mental State Examination (as follow, MMSE) screening tool score of 24 - 27 or Montreal Cognitive Assessment Japanese version (MoCA-J) screening tool score 25 or less in the pre-evaluation was designated [11]-[16]. The timing of the evaluation was HCT initiation (Base Line), 3 months later, 6 months later, 9 months later, 12 months later, 15 months later and 18 months later. The transition from MCI to dementia was judged by MMSE evaluation.

In addition to MMSE and Moca-J evaluations, $\mathrm{iADL}$ evaluations and evaluations of depression tendency were also conducted, and the transition of the evaluation points was also confirmed. Changes over time in the various evaluations after nine months were compared with those at the start. MMSE and MoCa-J score showed cognitive evaluation. Tokyo Metropolitan Institute of Gerontology (TMIG-index) of Competence [17] [18], which was iADL evaluation and Geriatric depression scale 15 (GDS15) [19] [20] were used too.

\subsubsection{MMSE Screening Tool}

MMSE was the most commonly used instrument for the assessment of cognitive function in both clinical and research settings. It was usually used as a screening test for dementia and cognitive impairment or as a brief cognitive assessment that takes about 10 min to complete. In Table 1, Instructions for administration 
and scoring of the MMSE were orientation (10 points), registration (3 points), attention and calculation ( 5 points), recall ( 3 points), language and praxis ( 9 points).

\subsubsection{MoCA Screening Tool}

The MoCa-J evaluation was the Japanese version of MoCA evaluation. The MoCA Test was validated in the setting of mild cognitive impairment (MCI), and has been subsequently adopted in numerous clinical settings. The sensivity of the MoCA for detecting MCI is $90 \%$, compared to $18 \%$ for other leading cognitive screening tools such as the MMSE. The MoCA assesses were short term memory, visuospatial abilities, executive functions, attention, concentration and working memory, language, orientation to time and place. Read list of words, subject must repeat them. Do 2 trials. Do a recall after 5 minutes.

\subsubsection{TMIG-Index of Competence}

Elderly populations are evaluated on their ability to perform instrumental activities of daily living (IADL) using one of three subscales in the TMIG Index of Competence, while the Basic Checklist-a tool developed to screen for frailty-is designed to measure actual task performance.

\subsubsection{GDS15}

Diagnosing depression in the elderly poses a serious problem because of the ageing process and various diseases that influence and mask symptoms of depressed mood. For instance, depression is often confused with dementia. It is therefore crucial to use a diagnostic tool that takes these problems into account. Symptoms of depression were assessed using the 15-item Geriatric Depression Scale (GDS-15) and demonstrated validity among ambulatory elderly.

\subsubsection{Surgical Therapists and Students}

3 occupational therapist and twenty healthy student volunteers (There was not a continuous disease; a having more than $90 \%$ of attendances of the required subject of the university student; 8 male and 12 females; mean age $20.4 \pm 0.7$ years) were enrolled.

Regarding the suitability of sample size, the significance level was set to 0.05 , and the method was a two-sided test, and the power for comparing the mean values of the two groups was calculated. As a result, the total power of $n=320$ were 0.99 . The power of each test plot was 0.64 for the $n=32$ plots and 0.41 for the $\mathrm{n}=20$ plots, which was less than 0.8 .

\section{Results}

Subjects were selected from the elderly who had not been diagnosed with dementia or MCI. According to MMSE and MoCa-J (MCI screening tools), there were more than one in four elderly people were classified as MCI or dementia.

As mentioned earlier, in general, the transition from MCI to dementia is about $10 \%$ per year. When comparing the evaluation of MMSE and MoCa-J 18 months 
later (VII) with BL, the average values of Group A and Group B showed a significant upward trend, placebo A was the status quo, and placebo B was It showed a tendency to decrease significantly (Table 1 , Table 2 ).

TIMG-Idex, which evaluates ADL, did not change significantly in all plots (Table 3). GDS, which evaluates the depression status of the elderly, was 4.1 to 4.6 on average for $\mathrm{BL}$, which was close to the depression tendency (5 or more). Placebo A and Placebo B were more depressed after 18 months, while Group A and Group B who underwent HCT showed a significant decrease (Table 4).

Table 1. MMSE changes over time every three months.

\begin{tabular}{|c|c|c|c|c|c|c|c|c|}
\hline & I. BL & II. $3 \mathrm{M}$ & III. $6 \mathrm{M}$ & IV. $9 \mathrm{M}$ & V. $12 \mathrm{M}$ & VI. $15 \mathrm{M}$ & VII. $18 \mathrm{M}$ & ANOVA \\
\hline Group A $(\mathrm{n}=24)$ & $25.5 \pm 3.3$ & $26.5 \pm 3.2$ & $26.6 \pm 3.1$ & $26.6 \pm 3.1$ & $26.9 \pm 3.2$ & $26.8 \pm 2.9$ & $27.1 \pm 2.7$ & $\mathrm{I}<\mathrm{VII}^{*}$ \\
\hline Placebo A $(n=22)$ & $23.5 \pm 3.6$ & $23.7 \pm 3.8$ & $23.0 \pm 3.7$ & $24.0 \pm 3.6$ & $22.8 \pm 3.6$ & $22.4 \pm 4.1$ & $22.1 \pm 4.1$ & - \\
\hline Group B $(n=32)$ & $26.3 \pm 2.3$ & $26.9 \pm 2.1$ & $27.4 \pm 1.8$ & $27.7 \pm 2.0$ & $27.6 \pm 2.1$ & $27.7 \pm 1.9$ & $28.0 \pm 1.7$ & $\begin{array}{l}\mathrm{I}<\mathrm{IV}^{*} \\
\mathrm{I}<\mathrm{V}^{*} \\
\mathrm{I}<\mathrm{VI}^{*} \\
\mathrm{I}<\mathrm{VII}^{*}\end{array}$ \\
\hline Placebo $B(n=20)$ & $23.8 \pm 3.5$ & $23.3 \pm 3.7$ & $22.7 \pm 3.7$ & $23.0 \pm 3.3$ & $22.0 \pm 3.1$ & $21.4 \pm 3.7$ & $20.3 \pm 3.8$ & $\begin{array}{l}\mathrm{I}>\mathrm{VI}^{*} \\
\mathrm{I}>\mathrm{VII}^{*}\end{array}$ \\
\hline
\end{tabular}

Mean value \pm standard deviation. ${ }^{*} p<0.05$. One-way analysis of variance, multiple comparison Tukey.

Table 2. MoCa-J changes over time every three months.

\begin{tabular}{|c|c|c|c|c|c|c|c|c|}
\hline & I. BL & II. $3 \mathrm{M}$ & III. $6 \mathrm{M}$ & IV. $9 \mathrm{M}$ & V. $12 \mathrm{M}$ & VI. $15 \mathrm{M}$ & VII. $18 \mathrm{M}$ & ANOVA \\
\hline & & & & & & & & $\mathrm{I}<\mathrm{V}^{*}$ \\
\hline \multirow[t]{2}{*}{ Group A $(n=24)$} & $19.9 \pm 2.5$ & $20.2 \pm 2.8$ & $21.0 \pm 3.5$ & $21.7 \pm 3.2$ & $21.9 \pm 3.0$ & $22.1 \pm 3.5$ & $22.9 \pm 3.2$ & $\mathrm{I}<\mathrm{VI}^{*}$ \\
\hline & & & & & & & & $\mathrm{I}<\mathrm{VII}^{*}$ \\
\hline Placebo A $(n=22)$ & $18.2 \pm 4.3$ & $17.2 \pm 4.5$ & $17.7 \pm 4.7$ & $17.5 \pm 4.8$ & $17.2 \pm 5.4$ & $16.0 \pm 5.3$ & $16.0 \pm 5.0$ & - \\
\hline Group B $(n=32)$ & $19.9 \pm 5.9$ & $21.3 \pm 4.9$ & $21.3 \pm 4.7$ & $21.1 \pm 5.2$ & $21.7 \pm 4.5$ & $22.2 \pm 4.8$ & $22.3 \pm 5.0$ & - \\
\hline Placebo B $(\mathrm{n}=20)$ & $18.7 \pm 4.3$ & $17.6 \pm 4.7$ & $18.0 \pm 4.8$ & $18.0 \pm 4.8$ & $17.4 \pm 4.3$ & $16.5 \pm 4.9$ & $15.4 \pm 4.2$ & $\mathrm{I}>\mathrm{VII}^{*}$ \\
\hline
\end{tabular}

Mean value \pm standard deviation. ${ }^{*} p<0.05$. One-way analysis of variance, multiple comparison Tukey.

Table 3. TIMG-Index changes over time every three months.

\begin{tabular}{ccccccccc}
\hline & I. BL & II. 3 M & III. 6 M & IV. 9 M & V. 12 M & VI. 15 M & VII. 18 M & ANOVA \\
\hline Group A ( $\mathrm{n}=24)$ & $6.3 \pm 2.6$ & $6.3 \pm 2.8$ & $6.3 \pm 2.4$ & $7.0 \pm 2.6$ & $7.7 \pm 2.6$ & $7.8 \pm 2.7$ & $7.9 \pm 2.4$ & - \\
Placebo A ( $\mathrm{n}=22)$ & $7.3 \pm 2.8$ & $5.5 \pm 3.5$ & $5.8 \pm 2.7$ & $6.7 \pm 2.7$ & $7.0 \pm 3.0$ & $6.3 \pm 2.0$ & $6.1 \pm 2.8$ & - \\
Group B ( $\mathrm{n}=32)$ & $11.8 \pm 1.6$ & $12.0 \pm 1.4$ & $11.9 \pm 1.5$ & $11.8 \pm 1.3$ & $11.8 \pm 1.6$ & $12.0 \pm 1.4$ & $12.0 \pm 1.3$ & - \\
Placebo B ( $\mathrm{n}=20)$ & $7.5 \pm 2.8$ & $7.2 \pm 3.1$ & $6.3 \pm 2.6$ & $6.9 \pm 2.6$ & $7.3 \pm 3.0$ & $6.5 \pm 2.7$ & $6.3 \pm 2.7$ & - \\
\hline
\end{tabular}

Mean value \pm standard deviation ${ }^{*} p<0.05$. One-way analysis of variance, multiple comparison Tukey. 
Table 4. GDS changes over time every three months.

\begin{tabular}{|c|c|c|c|c|c|c|c|c|}
\hline & I. BL & II. $3 \mathrm{M}$ & III. $6 \mathrm{M}$ & IV. $9 \mathrm{M}$ & V. $12 \mathrm{M}$ & VI. $15 \mathrm{M}$ & VII. $18 \mathrm{M}$ & ANOVA \\
\hline Group A $(\mathrm{n}=24)$ & $4.6 \pm 2.9$ & $4.4 \pm 3.6$ & $4.8 \pm 4.0-$ & $4.4 \pm 3.3$ & $4.4 \pm 2.8$ & $3.5 \pm 2.5$ & $2.8 \pm 2.1$ & $\mathrm{I}>\mathrm{VII}^{*}$ \\
\hline Placebo A $(\mathrm{n}=22)$ & $4.3 \pm 2.4$ & $6.1 \pm 4.6$ & $6.5 \pm 4.4$ & $6.6 \pm 4.1$ & $6.0 \pm 3.7$ & $7.3 \pm 3.9$ & $6.9 \pm 3.7$ & - \\
\hline Group B $(n=32)$ & $4.0 \pm 3.6$ & $3.5 \pm 2.6$ & $2.9 \pm 2.7$ & $2.8 \pm 2.5$ & $2.7 \pm 2.9$ & $2.1 \pm 1.8$ & $1.9 \pm 1.7$ & $\begin{array}{l}\mathrm{I}>\mathrm{VI}^{*} \\
\mathrm{I}>\mathrm{VII}^{*}\end{array}$ \\
\hline Placebo B $(n=20)$ & $4.1 \pm 2.5$ & $6.0 \pm 4.6$ & $6.3 \pm 4.4$ & $6.4 \pm 4.3$ & $5.8 \pm 3.8$ & $7.0 \pm 4.1$ & $6.9 \pm 3.8$ & $\mathrm{I}<\mathrm{VI}^{*}$ \\
\hline
\end{tabular}

Mean value \pm standard deviation. ${ }^{\star} p<0.05$. One-way analysis of variance, multiple comparison Tukey.

\section{Number of MMSE conversions (Figure 2)}

Group A $n=24$

The number of conversions for improvement from $\mathrm{BL}$ to $18 \mathrm{M}$ was $\mathrm{D}$ (equivalent to Dementia) to $\mathrm{H}$ (normal value) $1, \mathrm{D}$ to $\mathrm{M}$ (equivalent to $\mathrm{MCI}) 4$ and $\mathrm{M}$ to $\mathrm{H} 5$ (41.7\%). The number of conversions of deterioration was $\mathrm{M}$ to $\mathrm{D} 2, \mathrm{H}$ to $\mathrm{M} 1$ and $\mathrm{H}$ to $\mathrm{D} 0$ (12.5\%).

Placebo A $\mathrm{n}=22$

The number of conversions for improvement from BL to $18 \mathrm{M}$ was $\mathrm{D}$ to $0, \mathrm{D}$ to $\mathrm{M} 1$ and $\mathrm{M}$ to $\mathrm{H} 1$ (9.1\%). The number of conversions of deterioration was $\mathrm{M}$ to $\mathrm{D} 3, \mathrm{H}$ to $\mathrm{M} 2$ and $\mathrm{H}$ to $\mathrm{D} 0$ (22.7\%).

Group B $\mathrm{n}=32$

The number of conversions for improvement from $\mathrm{BL}$ to $18 \mathrm{M}$ was $\mathrm{D}$ to $2, \mathrm{D}$ to $\mathrm{M} 1$ and $\mathrm{M}$ to $\mathrm{H} 13$ (50.0\%). The number of conversions of deterioration was $\mathrm{M}$ to $\mathrm{D} 0, \mathrm{H}$ to $\mathrm{M} 2$ and $\mathrm{H}$ to $\mathrm{D} 0$ (6.3\%).

Placebo B $\mathrm{n}=20$

The number of conversions for improvement from $\mathrm{BL}$ to $18 \mathrm{M}$ was $\mathrm{D}$ to $0, \mathrm{D}$ to $\mathrm{M} 1$ and $\mathrm{M}$ to $\mathrm{H} 1$ (10.0). The number of conversions of deterioration was $\mathrm{M}$ to D8, $\mathrm{H}$ to $\mathrm{M} 4$ and $\mathrm{H}$ to D0 (60\%).

\section{Number of MoCa-J conversions (Figure 3)}

Group A $n=24$

The number of conversions for improvement from $\mathrm{BL}$ to $18 \mathrm{M}$ was $\mathrm{M}$ to $\mathrm{H} 6$ (25.0\%).

Placebo A $n=22$

The number of conversions for improvement from $\mathrm{BL}$ to $18 \mathrm{M}$ was $\mathrm{M}$ to $\mathrm{H} 2$ (9.1\%).

Group B n $=32$

The number of conversions for improvement from $\mathrm{BL}$ to $18 \mathrm{M}$ was $\mathrm{M}$ to $\mathrm{H} 9$ (28.1\%).

Placebo B $\mathrm{n}=20$

The number of conversions for improvement from BL to $18 \mathrm{M}$ was $\mathrm{M}$ to $\mathrm{H} 2$ (10.0\%).

Comparing the evaluation of TMIG 18 months later (VII) with BL, all groups showed a tendency to maintain the status quo. Comparing the evaluation of GDS at 18 months (VII) with BL, group A and group B showed a significant downward trend, and placebo B showed a significant upward trend. 

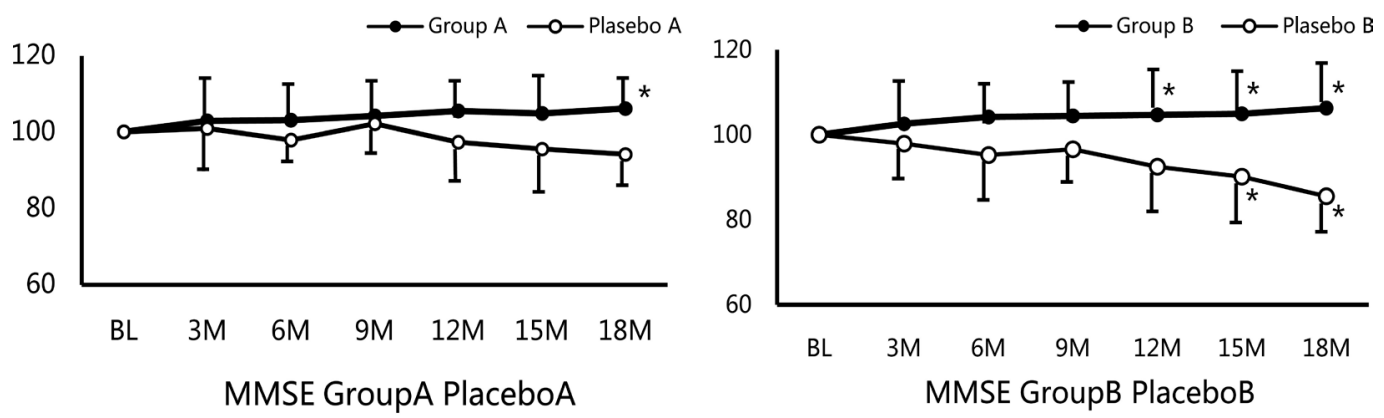

Mean \pm S.E, Group A $(\mathrm{n}=24)$, Placebo A $(\mathrm{n}=22)$, Group B $(\mathrm{n}=32)$, Placebo B $(\mathrm{n}=20),{ }^{\star} p<0.05$ vs BL $(100)$.

Figure 2. Change in MMSE average score evaluated every 3 months from BL.
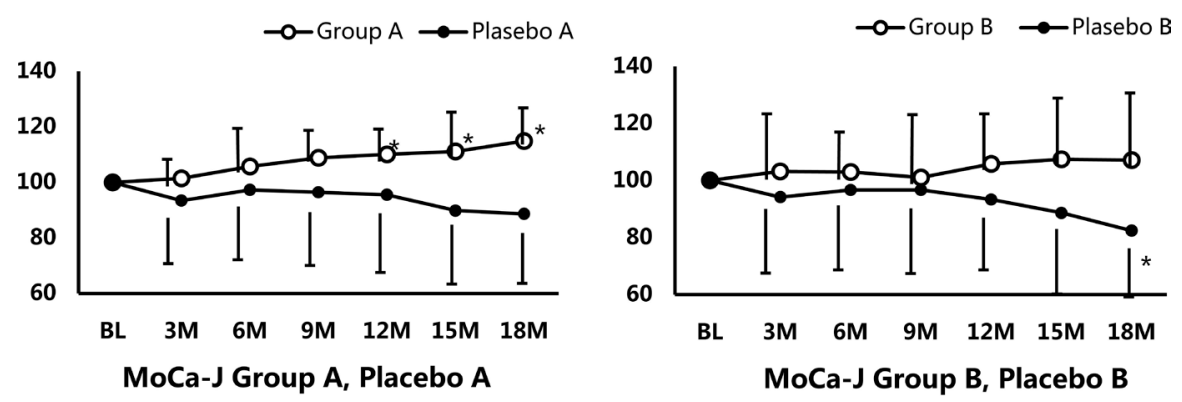

Mean \pm S.E, Group A $(\mathrm{n}=24)$, Placebo A $(\mathrm{n}=22)$, Group B $(\mathrm{n}=32)$, Placebo B $(\mathrm{n}=20),{ }^{*} p<0.05$ vs pre.

Figure 3. Change in MoCa-J average score evaluated every 3 months from BL.

\section{Discussion}

Cognitive impairment in MCI usually progresses year by year, and this study also showed progression of cognitive impairment in Placebo A and Placebo B. On the other hand, weekly HCT-provided MCI elderly, Group A and Group B, showed a tendency toward improvement in cognitive impairment after 18 months. It is considered that the factors were the healing effect of HCT, pleasant sensory stimulation from the tactile sensation to the brain, the psychological effect of building communication, and the improvement of the depression tendency.

Since the average GDS at BL was high, it was estimated that many of the MCI elderly living in the community had cognitive impairment due to senile depressive symptoms. Therefore, it was considered that the evaluation values of MMSE and MoCa-J were improved because the depressive symptoms were remarkably improved by the weekly HCT operation.

Although long-term evaluation was required, HCT was considered to have a preventive effect on the transition from MCI to dementia. In addition, although there was no significant difference, there was no decrease in IADL after 18 months in HCT subjects, and the suppressive effect on depressive tendency was observed, which is expected to have multifaceted effects of HCT.

In 2020, a global pandemic of COVID-19 was reported, with $20 \%$ of positive responders being severe and $80 \%$ being mild or asymptomatic. And it was also reported that COVID-19 tends to be more severe in older people and has a higher mortality rate [21] [22] [23] [24] [25]. 
As a matter of course, there are many reports that COVID-19 severely ill people often have weakened immunity due to the elderly and chronic diseases. HCT and touch care are said to promote the secretion of oxytocin, a well-being hormone in the brain [26] [27]. It has also been reported that oxytocin is also effective in building relationships [28] [29].

This HCT technique has the characteristic that true communication can be easily constructed because it can improve the euphoria of the treated side and the treated side. On the other hand, in order to prevent COVID-19 infection, it is unavoidable to cut off human interaction, but there are also reports that this often causes violence and divorce within the family [30]. In other words, it seems that it is necessary to share relaxation and healing in the home and to strengthen the autoimmune power by feeling happiness.

This HCT technique has the characteristic that true communication can be easily constructed because it can improve the euphoria of the treated side and the treated side. Therefore, it can be expected that the autoimmunity of all people involved can be improved, and it can be judged to be promising as a preventive technique and non-drug therapy for lifestyle-related diseases and various infectious diseases. COVID-19 infection is likely to spread to developing countries such as Africa in the future [31]. Although there is priority given to drug therapy and vaccination there, we would like to propose the use of HCT as a non-pharmacotherapy to prevent aggravation.

\section{Conflicts of Interest}

The authors declare no conflicts of interest regarding the publication of this paper.

\section{References}

[1] Wise, J.A. and Rosenberg, E.J. (1988) The Effects of Interior Treatments on Performance Stress in Three Types of Mental Tasks. Ctr. Integrated Facilities Res. Technical Rpt. No. 002-02-1988. Grand Valley State Univ., Allendale.

[2] Dixon, L.E., Mattons, R.H. and Jurich, A.P. (1987) Human Stress Reduction through Horticultural Vocational Training. HortScience, 22, 655-656.

[3] Ulrich, R.S., Simons, R.F., Losito, B.D., Fiorito, E., Miles, M.A. and Zelson, M. (1991) Stress Recovery during Exposure to Natural and Urban Environments. Journal of Environmental Psychology, 11, 201-230. https://doi.org/10.1016/S0272-4944(05)80184-7

[4] Song, J. and Sim, W. (1999) An Experimental Study on the Effects of Horticultural Therapy-With Special Reference to Negative Symptoms of Schizophrenia. In: Burchett, M.D., Tarran, J. and Wood, R., Eds., Towards a New Millennium in People-Plant Relationships, University of Technology, Sydney, 292-300.

[5] Koura, S., Furukawa, C., Yamagishi, K. and Nomura, J. (2002) An Attitude Survey of the University Students Who Participated as Volunteers in Horticultural Therapy at Some Welfare Facilities for Aged People. Journal of Japanese Society of People-Plant Relationships, 1, 25-27.

[6] Koura, S., Furukawa, C. and Nomura, J. (2002) Awareness Study of University Students Who Performed Horticultural Therapy in a Nursing Home. JSPPR Journal, 2, 12-16. 
[7] Koura, S. and Yamagishi, K. (2005) Stimulation Senses Evaluating Student Responses to Horticultural Therapeutic Activities and Blindfolded Harvest of Blueberry. ISHS Acta Horticulturae, 672, 185-189. https://doi.org/10.17660/ActaHortic.2005.672.21

[8] Kunikata, H. (2012) The Effects Measurement of Hand Massage by the Autonomic Activity and Psychological Indicators. The Journal of Medical Investigation, 59, 206-212. https://doi.org/10.2152/jmi.59.206

[9] Koura, S., Okawa, H., Oshikawa, T., Ueda, T., Nishikawa, C., Ikeda, A. and Kamijyo, K. (2018) Dementia Protective Efficacy by the Combination of Active and Passive Horticultural Therapy for All Person Concerned. International Symposium on Greener Cities for More Efficient Ecosystem Service in a Climate Changing World, Vol. 1, 223-231. https://doi.org/10.17660/ActaHortic.2018.1215.41

[10] Petersen, R.C., Smith, G.E., Waring, S.C., et al. (1999) Mild Cognitive Impairment: Clinical Characterization and Outcome. Archives of Neurology, 56, 303-308. https://doi.org/10.1001/archneur.56.3.303

[11] Espino, D.V., Lichtenstein, M.J., Palmer, R.F. and Hazuda, H.P. (2004) Evaluation of the Mini-Mental Status Examination's Internal Consistency in a Community-Based Sample of Mexican-American and European-American Elders: Results from the San Antonio Longitudinal Study of Aging. Journal of the American Geriatrics Society, 52, 822-827. https://doi.org/10.1111/j.1532-5415.2004.52226.x

[12] Folstein, M.F., Folstein, S.E. and McHugh, P.R. (1975) Mini-Mental State: A Practical Method for Grading the Cognitive State of Patients for the Clinician. Journal of Psychiatric Research, 12, 189-198. https://doi.org/10.1016/0022-3956(75)90026-6

[13] Ganguli, M., Ratcliff, G. and Huff, F.J. (1990) Serial Sevens versus World Backwards: A Comparison of the Two Measures of Attention from the MMSE. Journal of Geriatric Psychiatry and Neurology, 3, 203-207. https://doi.org/10.1177/089198879000300405

[14] Guerrero, B.E., Luo, X. and Schmeidler, J. (2009) The MMSE Orientation for Time Domain Is a Strong Predictor of Subsequent Cognitive Decline in the Elderly. International Journal of Geriatric Psychiatry, 24, 1429-1437. https://doi.org/10.1002/gps.2282

[15] Morales, L.S., Flowers, C., Gutierrez, P., Kleinman, M. and Teresi, J.A. (2006) Item and Scale Differential Functioning of the Mini-Mental Status Exam Assessed Using the Differential Item and Test Functioning (DFIT) Framework. Medical Care, 44, S143-S151. https://doi.org/10.1097/01.mlr.0000245141.70946.29

[16] Nasreddine, Z.S., Phillips, N.A., Bédirian, V., Charbonneau, S., Whitehead, V., Collin, I., Cummings, J.L. and Chertkow, H. (2005) The Montreal Cognitive Assessment, MoCA: A Brief Screening Tool for Mild Cognitive Impairment. Journal of the American Geriatrics Society, 53, 695-699. https://doi.org/10.1111/j.1532-5415.2005.53221.x

[17] Koyano, W., Shibata, H., Nakazato, K., Haga, H. and Suyama, Y. (1991) Measurement of Competence: Reliability and Validity of the TMIG Index of Competence. Archives of Gerontology and Geriatrics, 13, 103-116. https://doi.org/10.1016/0167-4943(91)90053-S

[18] Kumagai, S., Shibata, H., Watanabe, S., Suzuki, T., Haga, H., Osada, H. and Teraoka, K. (1999) An Intervention Trial to Postpone Aging in Competent Elderly. Trial of Nutritional Improvement in the Retirement Home. Nihon Koshu Eisei Zasshi, 46, 1003-1012. 
[19] Tanaka, C., Yoshida, H., Amano, H., Kumagai, S., Fujiwara, Y., Tsuchiya, Y. and Shinkai, S. (2006) Physical Activity Level and Physical, Mental and Social Factor in Community-Dwelling Elderly People. Japanese Journal of Public Health, 53, 671-680.

[20] Yang, Y. and Kwak, Y.T. (2016) The Effects of Donepezil on 15-Item Geriatric Depression Scale Structure in Patients with Alzheimer Disease. Dementia and Geriatric Cognitive Disorders Extra, 6, 437-446. https://doi.org/10.1159/000449244

[21] Verity, R., Okell, L.C., Dorigatti, I., Winskill, P., Whittaker, C., et al. (2020) Estimates of the Severity of Coronavirus Disease 2019: A Model-Based Analysis. The Lancet Infectious Disease, 20, 669-677. https://doi.org/10.1016/S1473-3099(20)30243-7

[22] WHO (2020) Report of the WHO-China Joint Mission on Coronavirus Disease 2019 (COVID-19).

https://www.who.int/publications-detail/report-of-the-who-china-joint-mission-on -coronavirus-disease-2019-(covid-19)

[23] WHO (2020) Coronavirus Disease 2019 (COVID-19) Situation Report 43. https://www.who.int/docs/default-source/coronaviruse/situation-reports/20200303sitrep-43-covid-19.pdf?sfvrsn=2c21c09c_2

[24] Jung, S., Akhmetzhanov, A.R., Hayashi, K., et al. (2020) Real-Time Estimation of the Risk of Death from Novel Coronavirus (COVID-19) Infection: Inference Using Exported Cases. Journal of Clinical Medicine, 9, E523. https://doi.org/10.3390/jcm9020523

[25] Famulare, M. (2020) 2019-nCoV: Preliminary Estimates of the Confirmed-CaseFatality-Ratio and Infection-Fatality-Ratio, and Initial Pandemic Risk Assessment.

[26] Moberg, U.K. (2000) The Oxytocin Factor: Tapping the Hormone of Calm, Love, and Healing. Journal of Midwifery \& Women's Health, 50, e6. https://doi.org/10.1016/j.jmwh.2004.07.002

[27] Moberg, U.K., Handlin, L. and Petersson, M. (2014) Self-Soothing Behaviors with Particular Reference to Oxytocin Release induced by Non-Noxious Sensory Stimulation. Frontiers in Psychology, 5, 1529. https://doi.org/10.3389/fpsyg.2014.01529

[28] Matthiesen, A.S., Ransjö, A.B., Nissen, E. and Uvnäs, M.K. (2001) Postpartum Maternal Oxytocin Release by Newborns: Effects of Infant Hand Massage and Sucking. Birth, 28, 13-19. https://doi.org/10.1046/j.1523-536x.2001.00013.x

[29] Light, K.C., Grewen, K.M. and Amico, J.A. (2005) More Frequent Partner Hugs and Higher Oxytocin Levels Are Linked to Lower Blood Pressure and Heart Rate in Premenopausal Women. Biological Psychology, 69, 5-21. https://doi.org/10.1016/j.biopsycho.2004.11.002

[30] WHO (2020) COVID-19 and Violence against Women What the Health Sector/System Can Do. https://apps.who.int/iris/bitstream/handle/10665/331699/WHO-SRH-20.04-eng.pdf

[31] WHO (2020) African Countries Move from COVID-19 Readiness to Response as Many Confirm Cases. https://www.afro.who.int/health-topics/coronavirus-covid-19 